\title{
Design for Ti-Al-V-Mo-Nb alloys for laser additive manufacturing based on a cluster model and on their microstructure and properties
}

\author{
Tian-yu Liu', Zhi-hao Zhu', Shuang Zhang'2, Xiao-hua Min', *Chuang Dong', \\ 1. School of Materials Science and Engineering, Dalian University of Technology, Dalian 116024, Liaoning, China \\ 2. School of Materials Science and Engineering, Dalian Jiaotong University, Dalian 116028, Liaoning, China
}

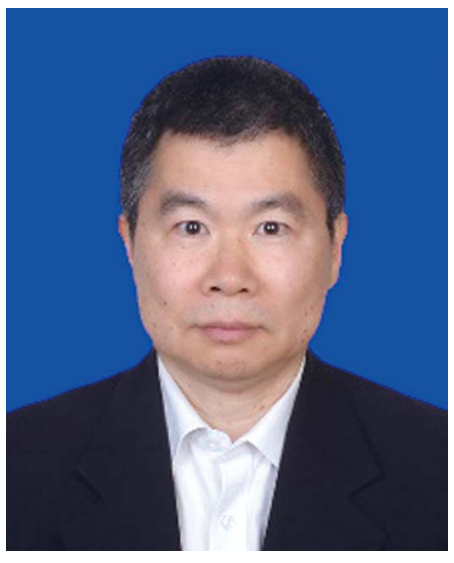

${ }^{*}$ Chuang Dong

Male, Ph. D, Professor. His research interests mainly focus on structural modeling of disordered materials, alloy design, and surface modification. Pro. Dong owned the title of the Outstanding Young Researcher in 1995 and Changjiang Professor in 2005, respectively.

E-mail: dong@dlut.edu.cn

Received: 2021-04-13

Accepted: 2021-08-12
Abstract: In this study, $\alpha+\beta$ Ti-Al-V-Mo-Nb alloys with the addition of multiple elements that are suitable for laser additive manufacturing (LAM) were designed according to a Ti-6Al-4V cluster formula. This formula can be expressed as 12[Al- $\left.\mathrm{Ti}_{12}\right]\left(\mathrm{AlTi}_{2}\right)+5[\mathrm{Al}-$ $\left.\mathrm{Ti}_{14}\right]\left((\mathrm{Mo}, \mathrm{V}, \mathrm{Nb})_{2} \mathrm{Ti}\right)$, in which $\mathrm{Mo}$ and $\mathrm{Nb}$ were added into the alloys partially instead of $\mathrm{V}$ to give alloys with nominal compositions of Ti-6.01Al-3.13V-1.43Nb, Ti-5.97Al2.33V-2.93Mo, and Ti-5.97 Al-2.33V-2.20Mo-0.71 Nb (wt.\%). The microstructures and mechanical properties of the as-deposited and heat-treated samples prepared via LAM were examined. The sizes of the $\beta$ columnar grains and $\alpha$ laths in the $\mathrm{Nb}$ containing samples are found to be larger than those of the Ti-6Al-4V alloy, whereas Mo- or Mo/Nb-added alloys contain finer grains. It indicates that $\mathrm{Nb}$ gives rise to coarsened $\beta$ columnar grains and $\alpha$ laths, while Mo significantly refines them. Furthermore, the single addition of $\mathrm{Nb}$ improves the elongation, whereas the single addition of Mo enhances the strength of the alloys. The simultaneous addition of Mo/Nb significantly improves the comprehensive mechanical properties of the alloys, leading to the best properties with an ultimate tensile strength of $1,070 \mathrm{MPa}$, a yield strength of $1,004 \mathrm{MPa}$, an elongation of $9 \%$, and micro-hardness of $355 \mathrm{HV}$. The fracture modes of all the alloys are ductile-brittle mixed fracture.

Key words: titanium alloy; laser additive manufacturing; cluster-plus-glue-atom model; composition design; microstructure; mechanical properties

CLC numbers: TG146.23; Document code: A; Article ID: 1672-6421 2021 04-424-09

\section{Introduction}

Ti-6Al-4V alloy was successfully designed and manufactured in the United States in $1954^{[1]}$, and since then, has been widely applied in aerospace, petrochemical, and biomedical fields due to its high strength-to-weight ratio, good corrosion resistance, and excellent biocompatibility ${ }^{[2-4]}$. However, traditional processes (involving casting, forging, and rolling) for fabricating large and complex Ti-6Al-4V alloy parts are fair labor-intensive and time consuming. Recently, laser additive manufacturing (LAM) has attracted great attention due to the construction of three-dimensional parts in a layer-bylayer fashion ${ }^{[5-7]}$. This allows for the opportunity to eliminate multiple assembly steps, reduce part count, reduce material waste, and improve lead-time for functional end-use parts. However, the current titanium alloys used for LAM are the industrial alloys, mainly designed to be cast or wrought, and barely of notice for the special LAM process.

Recently, many studies ${ }^{[8-10]}$ have reported a variety of newly-designed titanium alloys suitable for LAM. Vrancken et al. ${ }^{[11]}$ designed a Ti-6Al-4V-10Mo alloy, prepared the alloy samples using selective laser melting (SLM), and found that its mechanical properties were better than the conventional $\beta$ titanium alloys. Li et al. ${ }^{[12]}$ designed a novel $\alpha+\beta$ Ti$6 \mathrm{Al}-2 \mathrm{~V}-1.5 \mathrm{Mo}-0.5 \mathrm{Zr}-0.3 \mathrm{Si}$ alloy. Its strength and elongation were superior than $\mathrm{Ti}-6 \mathrm{Al}-4 \mathrm{~V}$ due 
to a strong solid solution strengthening caused by the addition of Mo, $\mathrm{Zr}$ and Si. Yu et al. ${ }^{[13]}$ designed Ti-Zr alloys (Ti20Zr, Ti30Zr, Ti40Zr, Ti50Zr and Ti60Zr, at.\%) by trial-and-error route, and produced samples using LAM, and found Ti-40Zr alloy showed an excellent balanced performance of elongation, corrosion resistance, and formability. However, titanium alloys used for LAM design via this trial-and-error route are quite labour-intensive and time-consuming.

To effectively develop high-performance Ti alloys, the cluster-plus-glue-atom model for describing short range order structures could be used ${ }^{[14,15]}$. Generally, the cluster-plus-glueatom model involves the nearest neighbors and a few outer-shell atoms, described as [cluster] (glue atoms) ${ }_{x}{ }^{[16]}$. The position of solute elements in the cluster-plus-glue-atom model depends on their interactions with the solvent elements, characterized by the enthalpy of mixing $\Delta H^{[17]}$. For example, the solute element $\mathrm{Nb}$, with weak interaction with $\mathrm{Ti}\left(\Delta H_{\mathrm{Ti}-\mathrm{Nb}}=2 \mathrm{~kJ} \cdot \mathrm{mol}^{-1}\right)$, is filled at the cluster glue atom position. By contrast, the solute elements Mo and $\mathrm{Sn}$, with strong interactions with $\mathrm{Ti}\left(\Delta H_{\mathrm{Ti}-\mathrm{Mo}}=-4 \mathrm{~kJ} \cdot \mathrm{mol}^{-1}\right.$, $\left.\Delta H_{\mathrm{Ti}-\mathrm{Sn}}=-21 \mathrm{~kJ} \cdot \mathrm{mol}^{-1}\right)$, are filled at the cluster center position. Due to $\mathrm{Zr}$ and Ti being in the same group, Ti of the cluster shell or the glue atom can be replaced by Zr. Hence, a novel alloy based on the cluster formula $\left[\left(\mathrm{Mo}_{0.5}, \mathrm{Sn}_{0.5}\right)-\mathrm{Ti}_{13} \mathrm{Zr}_{1}\right] \mathrm{Nb}_{1}$ presents the lowest Young's modulus (48 GPa) ${ }^{[18]}$. The cluster-plus-glueatom model has been proven to be useful for the composition design of the alloy ${ }^{[19,20]}$.

In this work, Ti-Al-V-Mo-Nb alloys were determined with the formula $12\left[\mathrm{Al}_{-} \mathrm{Ti}_{12}\right]\left(\mathrm{AlTi}_{2}\right)+5\left[\mathrm{Al}_{-} \mathrm{Ti}_{14}\right]\left((\mathrm{V}, \mathrm{Mo}, \mathrm{Nb})_{2} \mathrm{Ti}\right)$ using $\mathrm{Nb} /$ Mo to partially replace $\mathrm{V}$ in the cluster composition of Ti-6Al-4V alloy, and prepared by LAM process. The microstructure, microhardness, and room temperature tensile properties of the asdeposited and heat-treated alloy samples were studied.

\section{Experimental procedure}

\subsection{Composition design}

Ti-6Al-4V alloy was selected as a basic alloy to develop a novel alloy based on the cluster-plus-glue-atom model. This alloy comprises two solid solution phases, namely an $\alpha$ phase with a hexagonal close-packed crystal structure, and a $\beta$ phase with a body-centered cubic structure, where the $\alpha$ phase cluster formula is $\left[\mathrm{Al}_{-} \mathrm{Ti}_{12}\right]\left(\mathrm{AlTi}_{2}\right)$ and the $\beta$ phase formula is $\left[\mathrm{Al}-\mathrm{Ti}_{14}\right]$ $\left(\mathrm{V}_{2} \mathrm{Ti}\right)$. Mimicking the atomic-level resonance model of solid solution alloys, where the two structural units of $\alpha$ and $\beta$ are treated as hard spheres of different radii, calculations give a unit of 17 hard spheres, which leads to the cluster composition formula $12\left[\mathrm{Al}_{-} \mathrm{Ti}_{12}\right]\left(\mathrm{AlTi}_{2}\right)+5\left[\mathrm{Al}-\mathrm{Ti}_{14}\right]\left(\mathrm{V}_{2} \mathrm{Ti}\right)$ for Ti-6.05Al$3.94 \mathrm{~V}$ (wt.\%) ${ }^{[21]}$. Furthermore, Ti-Al-V-Mo-Nb alloys can be designed using the Ti-6Al-4V cluster formula, with the following steps:

The first step is related to the construction of the cluster formula of a solid solution. Mo, $\mathrm{V}$, and $\mathrm{Nb}$ tend to form $\beta$ clusters due to their serving as isomorphous $\beta$ stable elements. Furthermore, considering the mixing enthalpy between each isomorphous $\beta$ element and $\mathrm{Ti}\left(\Delta H_{\mathrm{Ti}-\mathrm{Mo}}=-4 \mathrm{~kJ} \cdot \mathrm{mol}^{-1}, \Delta H_{\mathrm{Ti}-\mathrm{V}}=-2 \mathrm{~kJ} \cdot \mathrm{mol}^{-1}\right.$, and
$\left.\Delta H_{\mathrm{Ti}-\mathrm{Nb}}=2 \mathrm{~kJ} \cdot \mathrm{mol}^{-1}\right), \mathrm{Mo}, \mathrm{V}$, and $\mathrm{Nb}$ have weaker interactions with solvent $\mathrm{Ti}$, and tend to occupy the $\beta$ cluster glue atom position. Therefore, the $\beta$ cluster results in the formation of $\left[\mathrm{Al}-\mathrm{Ti}_{14}\right]\left((\mathrm{Mo}, \mathrm{V}, \mathrm{Nb})_{2} \mathrm{Ti}\right)$ and the Ti-Al-V-Mo-Nb cluster formula results in the formation of $12\left[\mathrm{Al}_{-} \mathrm{Ti}_{12}\right]\left(\mathrm{AlTi}_{2}\right)+5\left[\mathrm{Al}-\mathrm{Ti}_{14}\right]$ $\left((\mathrm{Mo}, \mathrm{V}, \mathrm{Nb})_{2} \mathrm{Ti}\right)$.

The next step is to define a proper cluster. It is worth mentioning that the solidification range is usually used to predict the likelihood of cracks forming during solidification ${ }^{[2]}$. As is known, the fluidity of solid solution alloys is worse than that of eutectic alloys and pure metals. With an increase in the solidification range, the morphology of crystal growth changes from a smooth interface to dendrites. Dendrites can severely hinder the flow of the alloy melt, leading to less liquid being available in the interdendritic feed during the last stage of solidification, and thus cracks are more likely to appear in the alloy. Based on the Scheil-Gulliver model, the solidification range $(\Delta T)$ of the designed alloy can be calculated using JMatPro software, with results as shown in Fig. 1. Ti-Al$\mathrm{V}-\mathrm{Mo}-\mathrm{Nb}$ alloys were designed using the cluster-plus-glueatom model, with Ti-6.05Al-3.94V (Ti-6Al-4V, wt.\%) set as a reference alloy. The nominal chemical compositions designed are listed in Table 1 for Ti-Al-V-Mo-Nb billets with different $\beta$ clusters of $5\left[\mathrm{Al}-\mathrm{Ti}_{14}\right]\left(\mathrm{V}_{2} \mathrm{Ti}\right), 5\left[\mathrm{Al}-\mathrm{Ti}_{14}\right]\left(\mathrm{V}_{1.6} \mathrm{Nb}_{0.4} \mathrm{Ti}\right), 5\left[\mathrm{Al}-\mathrm{Ti}_{14}\right]$ $\left(\mathrm{V}_{1.2} \mathrm{Mo}_{0.8} \mathrm{Ti}\right), 5\left[\mathrm{Al}-\mathrm{Ti}_{14}\right]\left(\mathrm{V}_{1.2} \mathrm{Mo}_{0.6} \mathrm{Nb}_{0.2} \mathrm{Ti}\right) . \mathrm{Ti}-6.05 \mathrm{Al}-3.94 \mathrm{~V}$ (wt.\%), Ti-6.01Al-3.13V-1.43Nb (wt.\%), Ti-5.97Al-2.33V2.93Mo (wt.\%), and Ti-5.97Al-2.33V-2.20Mo-0.71 Nb (wt.\%), abbreviated as Ti-6Al-4V, $1.4 \mathrm{Nb}, 3 \mathrm{Mo}$, and $2 \mathrm{Mo}-1 \mathrm{Nb}$ in this study, respectively. It is obvious that the solidification ranges of liquid-solid two-phase region of the $1.4 \mathrm{Nb}, 3 \mathrm{Mo}$, and $2 \mathrm{Mo}-$ $1 \mathrm{Nb}$ alloys are $10.72{ }^{\circ} \mathrm{C}, 10.66^{\circ} \mathrm{C}$, and $10.01{ }^{\circ} \mathrm{C}$, respectively, which are narrower than that of the Ti-6Al-4V alloy $\left(13.31^{\circ} \mathrm{C}\right)$.

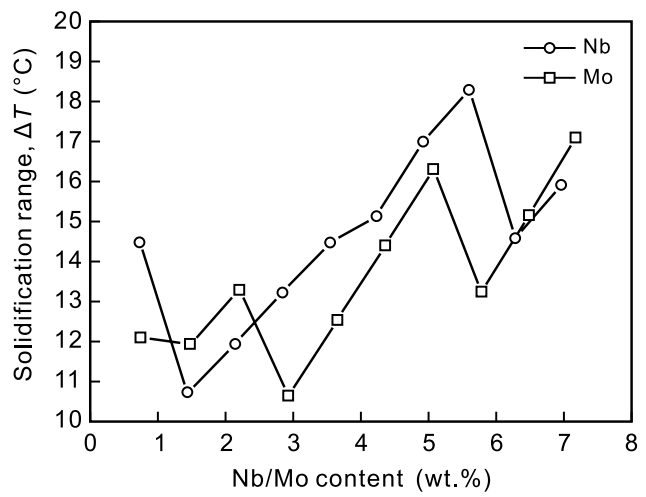

Fig. 1: Changes in calculated solidification range of liquid-solid two-phase region in Ti-Al-V-Mo-Nb alloys with different amounts of Mo and $\mathrm{Nb}$

\subsection{Laser additive manufacturing}

$\mathrm{Ti}$ and $\mathrm{Al}$ powder particles with a size range of $50-150 \mu \mathrm{m}$, and $\mathrm{V}, \mathrm{Nb}$, and Mo powder particles with a size range of 50$75 \mu \mathrm{m}$ were used to prepare Ti-Al-V-Mo-Nb alloys. According to the designed compositions, powders of the elements were mixed for $4 \mathrm{~h}$ in a blending machine and were then dried at $400 \mathrm{~K}$ for $12 \mathrm{~h}$ in a vacuum drying furnace. A commercial Ti$6 \mathrm{Al}-4 \mathrm{~V}$ plate with the size of $140 \mathrm{~mm} \times 100 \mathrm{~mm} \times 20 \mathrm{~mm}$ was 
Table 1: Designed cluster formulas and their compositions and solidification range $(\Delta T)$

\begin{tabular}{cccc} 
Alloy & Cluster formulas $($ at. \%) & Compositions (wt.\%) & $\Delta T\left({ }^{\circ} \mathrm{C}\right)$ \\
\hline Ti-6Al-4V & $\left.12\left[\mathrm{Al}^{\left.-\mathrm{Ti}_{1}\right]}\right](\mathrm{AlTi})_{2}\right)+5\left[\mathrm{Al}-\mathrm{Ti}_{14}\right]\left(\mathrm{V}_{2} \mathrm{Ti}\right)$ & $\mathrm{Ti}-6.05 \mathrm{Al}-3.94 \mathrm{~V}$ & 13.31 \\
$1.4 \mathrm{Nb}$ & $12\left[\mathrm{Al}-\mathrm{Ti}_{12}\right]\left(\mathrm{AlTi}_{2}\right)+5\left[\mathrm{Al}-\mathrm{Ti}_{14}\right]\left(\mathrm{V}_{1.6} \mathrm{Nb}_{0.4} \mathrm{Ti}\right)$ & $\mathrm{Ti}-6.01 \mathrm{Al}-3.13 \mathrm{~V}-1.43 \mathrm{Nb}$ & 10.72 \\
$3 \mathrm{Mo}$ & $12\left[\mathrm{Al}-\mathrm{Ti}_{12}\right]\left(\mathrm{AlTi}_{2}\right)+5\left[\mathrm{Al}-\mathrm{Ti}_{14}\right]\left(\mathrm{V}_{1.2} \mathrm{Mo}_{0.8} \mathrm{Ti}\right)$ & $\mathrm{Ti}-5.97 \mathrm{Al}-2.33 \mathrm{~V}-2.93 \mathrm{Mo}$ & 10.66 \\
$2 \mathrm{Mo}-1 \mathrm{Nb}$ & $12\left[\mathrm{Al}-\mathrm{Ti}_{12}\right]\left(\mathrm{AlTi}_{2}\right)+5\left[\mathrm{Al}-\mathrm{Ti}_{14}\right]\left(\mathrm{V}_{1.2} \mathrm{Mo}_{0.6} \mathrm{Nb}_{0.2} \mathrm{Ti}\right)$ & $\mathrm{Ti}-5.97 \mathrm{Al}-2.33 \mathrm{~V}-2.20 \mathrm{Mo}-0.71 \mathrm{Nb}$ & 10.01
\end{tabular}

selected as the substrate during the LAM process which was carried out in a glove box under a controlled environment using a $6 \mathrm{~kW}$ fiber laser (YLS-6000). To prevent the oxidation of the samples, the chamber was filled with argon gas. The processing parameters of the process were as follows: laser power of $1,800 \mathrm{~W}$, scanning speed of $480 \mathrm{~mm} \cdot \mathrm{min}^{-1}$, overlap ratio of $30 \%$, and a zigzag pattern scanning strategy. A series of bulk samples $(57 \mathrm{~mm} \times 15 \mathrm{~mm} \times 13 \mathrm{~mm}$ ) were layer-by-layer deposited using the above parameters, as shown in Fig. 2.

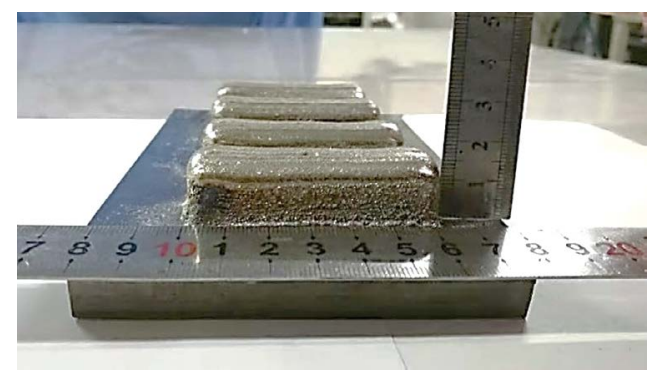

Fig. 2: Macrographs of bulk LAM Ti-6AI-4V samples

\subsection{Microstructural characterization}

The LAM samples were divided into two groups of asdeposited and heat-treated samples. For heat-treated samples, firstly, the samples were annealed at $980{ }^{\circ} \mathrm{C}$ for $1 \mathrm{~h}$, followed by furnace cooling. Then, to obtain a large amount of $\alpha_{\mathrm{s}}$ (secondary $\alpha$ ), the samples were heated to $920^{\circ} \mathrm{C}$ and held for $1 \mathrm{~h}$, followed by air cooling, and aging heat treatment at $600^{\circ} \mathrm{C}$ for $4 \mathrm{~h}$, followed by air cooling.

The phase constitutions of the samples were detected using a BRUKER X-ray diffractometer (XRD) equipped with a $\mathrm{Cu}$ $\mathrm{K} \alpha$ radiation source and operating at $40 \mathrm{kV}$ and $40 \mathrm{~mA}$, at a scanning rate of $4^{\circ} \cdot \mathrm{min}^{-1}$ over a $2 \theta$ angle range of $20^{\circ}-100^{\circ}$. The XRD measurements were performed on a cross section in the middle of the bulk samples. The microstructures of the samples after grinding using $\mathrm{SiC}$ paper, and then polishing using a $\mathrm{SiO}_{2}-\mathrm{H}_{2} \mathrm{O}_{2}$ solution, and etching with $3 \% \mathrm{HF}+7 \%$ $\mathrm{HNO}_{3}+90 \% \mathrm{H}_{2} \mathrm{O}$ (volume fraction) were observed by an OLYMPUS optical microscope (OM) and a Zeiss Supra55 scanning electron microscope (SEM). OM observations were performed on a longitudinal section from the middle of the bulk samples, and SEM observations were performed on a cross section from the middle of the bulk samples. The sizes of the prior- $\beta$ grains and $\alpha$ phases were measured from $\mathrm{OM}$ and SEM images using Image-Pro Plus 6.0 software.

\subsection{Testing of mechanical properties}

Uniaxial tensile testing of the as-deposited and heat-treated samples was conducted on a UTM5504 electronic universal testing machine at a strain rate of $2.8 \times 10^{-4} \mathrm{~s}^{-1}$ at room temperature. Tensile samples with a gauge size of $49 \mathrm{~mm} \times 10 \mathrm{~mm} \times 2 \mathrm{~mm}$ were cut from cross sections of the middle of the bulk samples, as shown in Fig. 3. The fracture morphologies of these tensile samples were observed using SEM. Moreover, micro-hardness testing of all the samples was conducted by the HVS-1000 apparatus with the load of $300 \mathrm{~g}$ dwelling for $15 \mathrm{~s}$, wherein each sample was tested at least 10 times. Micro-hardness tests were also performed on cross sections from the middle of the bulk samples.

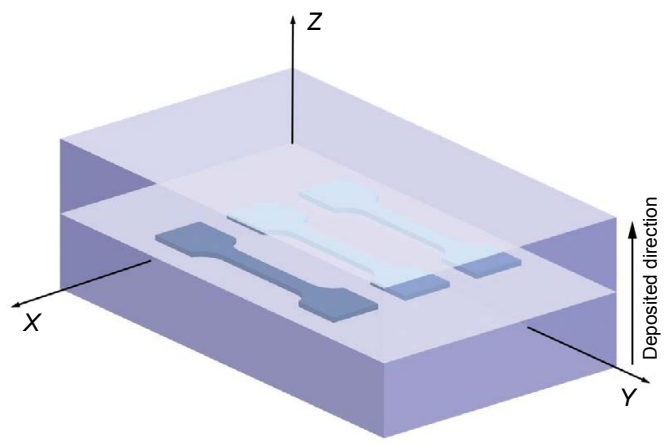

Fig. 3: Sampling diagram of uniaxial tensile testing

\section{Results and discussion}

\subsection{Phase identification}

Figure 4 shows XRD diffraction patterns of the as-deposited and heat-treated Ti-Al-V-Mo-Nb samples prepared by LAM. As shown in Fig. 4(a), the as-deposited $1.4 \mathrm{Nb}$ alloy mainly consists of $\alpha$ phase, whereas the peaks associated with the $\beta$ phase fail to be observed, mainly because $\mathrm{Nb}$ is the weaker $\beta$ stable element resulting in the low amount of $\beta$ phase. Based on the XRD results in Fig. 4(a), the peaks of $\beta$ phases are very weak, indicating the amount of $\beta$ phases in the as-deposited Ti-6Al-4V, 3Mo, and $2 \mathrm{Mo}-1 \mathrm{Nb}$ alloys is very small. After the heat treatment, the peaks of $\beta$ phases increase, the content of $\beta$ phases increases, but $\alpha$ phase is still dominant.

\subsection{Microstructure of prior- $\beta$ and primary $\alpha$ phases}

Figure 5 shows OM images of a longitudinal section from the middle of the as-deposited samples. The microstructure mainly features columnar prior- $\beta$ grains, which grow epitaxially from 
(a)

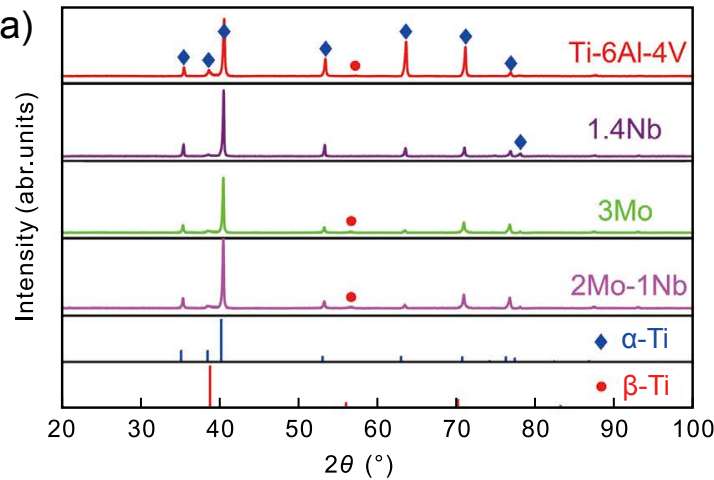

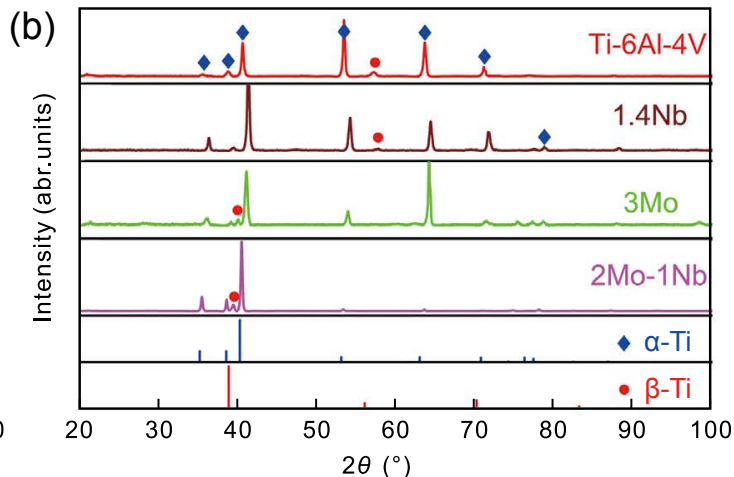

Fig. 4: XRD diffraction patterns of as-deposited and heat-treated samples of Ti-Al-V-Mo-Nb alloys: (a) as-deposited samples; (b) heat-treated samples

the substrate along the deposition $Z$-direction. There are two reasons for the formation of columnar $\beta$ grains. On the one hand, grain grows preferentially in the direction of the fastest heat dissipation. The heat dissipation from the substrate is quicker than that of atmosphere and along the build direction, which contributes to the formation of columnar grains along the deposition direction. On the other hand, the narrow solidification range is conducive to the formation of columnar grains.
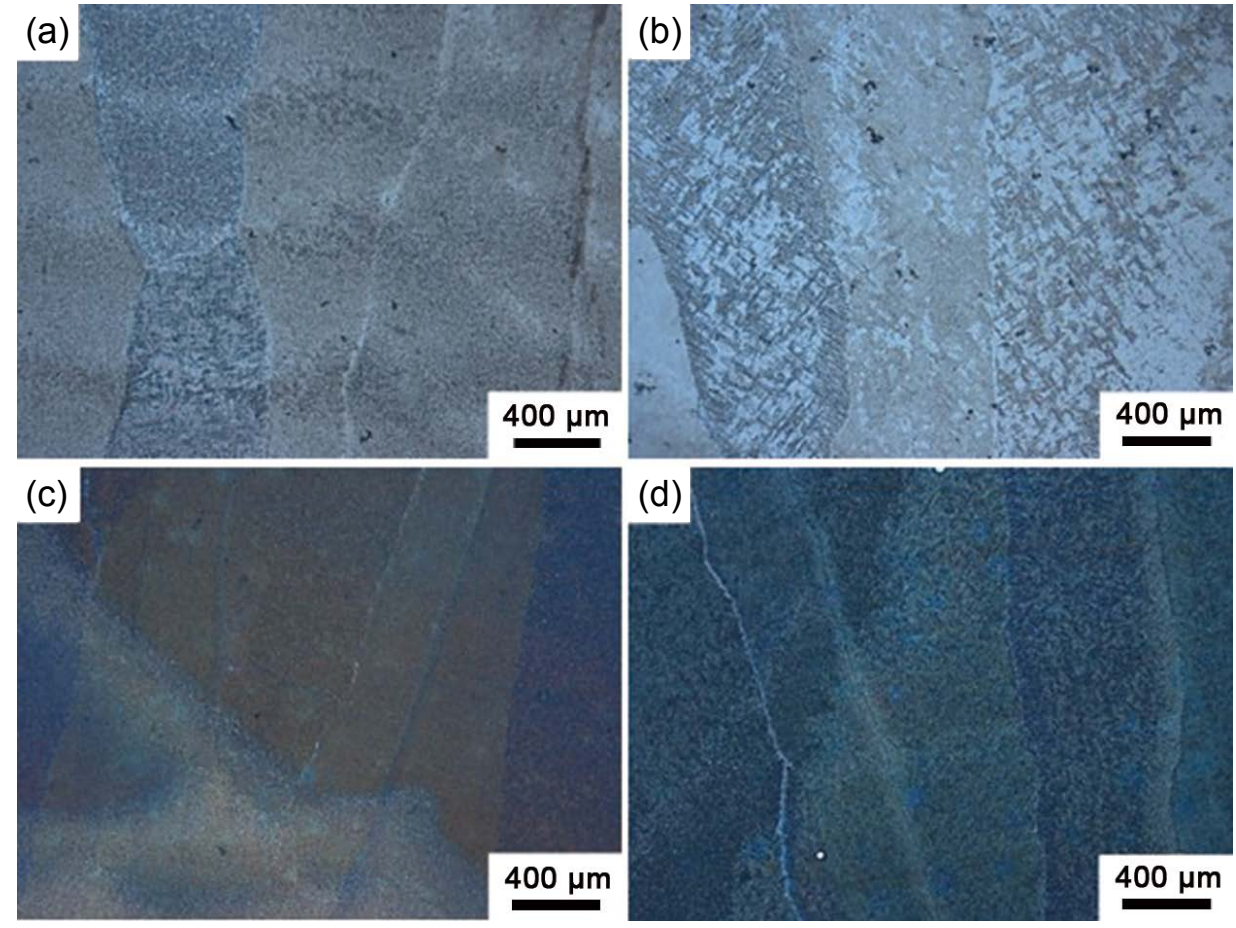

Fig. 5: OM images of as-deposited Ti-Al-V-Mo-Nb alloys: (a) Ti-6Al-4V; (b) 1.4Nb; (c) 3Mo; (d) 2Mo-1 Nb

Figure 6 shows SEM images of the cross section in the middle of the as-deposited and heat-treated samples. From Fig. 6, it is evident that all the as-deposited samples exhibit an ultrafine basket-weave microstructure consisting of striplike $\alpha$ phase and remanent $\beta$ phases, as shown in Fig. 6(a-d). After heat treatment [Fig. $6\left(a^{\prime}, b^{\prime}\right.$, and $\left.d^{\prime}\right)$ ], the prior- $\beta$ grains microstructure is made up of $\alpha$ laths and an equiaxed $\alpha$ phase in the Ti- $6 \mathrm{Al}-4 \mathrm{~V}, 1.4 \mathrm{Nb}$, and $2 \mathrm{Mo}-1 \mathrm{Nb}$ alloys, and there is a significant reduction in their aspect ratios compared with each as-deposited sample. Particularly, the microstructure in $3 \mathrm{Mo}$ alloy is composed of fine stripe-like $\alpha$ laths and small secondary $\alpha$ phases, as shown in Fig. 6(c'). Furthermore, compared with the as-deposited samples, the heat-treated samples comprise a larger volume fraction of lamellar $\left(\alpha_{\mathrm{s}}+\beta\right)$ microstructure. It should also be noted that the width of $\alpha_{\mathrm{s}}$ is much smaller than that of the primary $\alpha$ phase in the heat-treated samples.

Figure 7 shows the changes in the sizes of prior- $\beta$ grains, primary $\alpha$ phases, aspect ratio of $\alpha$ phases and the width of secondary $\alpha$ phases of Ti-Al-V-Mo-Nb alloys. The widths of the prior- $\beta$ grains in the as-deposited Ti- $6 \mathrm{Al}-4 \mathrm{~V}, 1.4 \mathrm{Nb}, 3 \mathrm{Mo}$, and $2 \mathrm{Mo}-1 \mathrm{Nb}$ alloys are approximately $661 \mu \mathrm{m}, 737 \mu \mathrm{m}, 351$ $\mu \mathrm{m}$, and $552 \mu \mathrm{m}$, respectively, as shown in Fig. 7(a). For the asdeposited samples, the sizes of the primary $\alpha$ phases in the Ti$6 \mathrm{Al}-4 \mathrm{~V}, 1.4 \mathrm{Nb}, 3 \mathrm{Mo}$, and $2 \mathrm{Mo}-1 \mathrm{Nb}$ alloys are $0.95 \mu \mathrm{m}, 1.3 \mu \mathrm{m}$, $0.24 \mu \mathrm{m}$, and $0.53 \mu \mathrm{m}$, respectively. For the heat-treated samples, the sizes of the primary $\alpha$ phases in the Ti- $6 \mathrm{Al}-4 \mathrm{~V}, 1.4 \mathrm{Nb}, 3 \mathrm{Mo}$, 

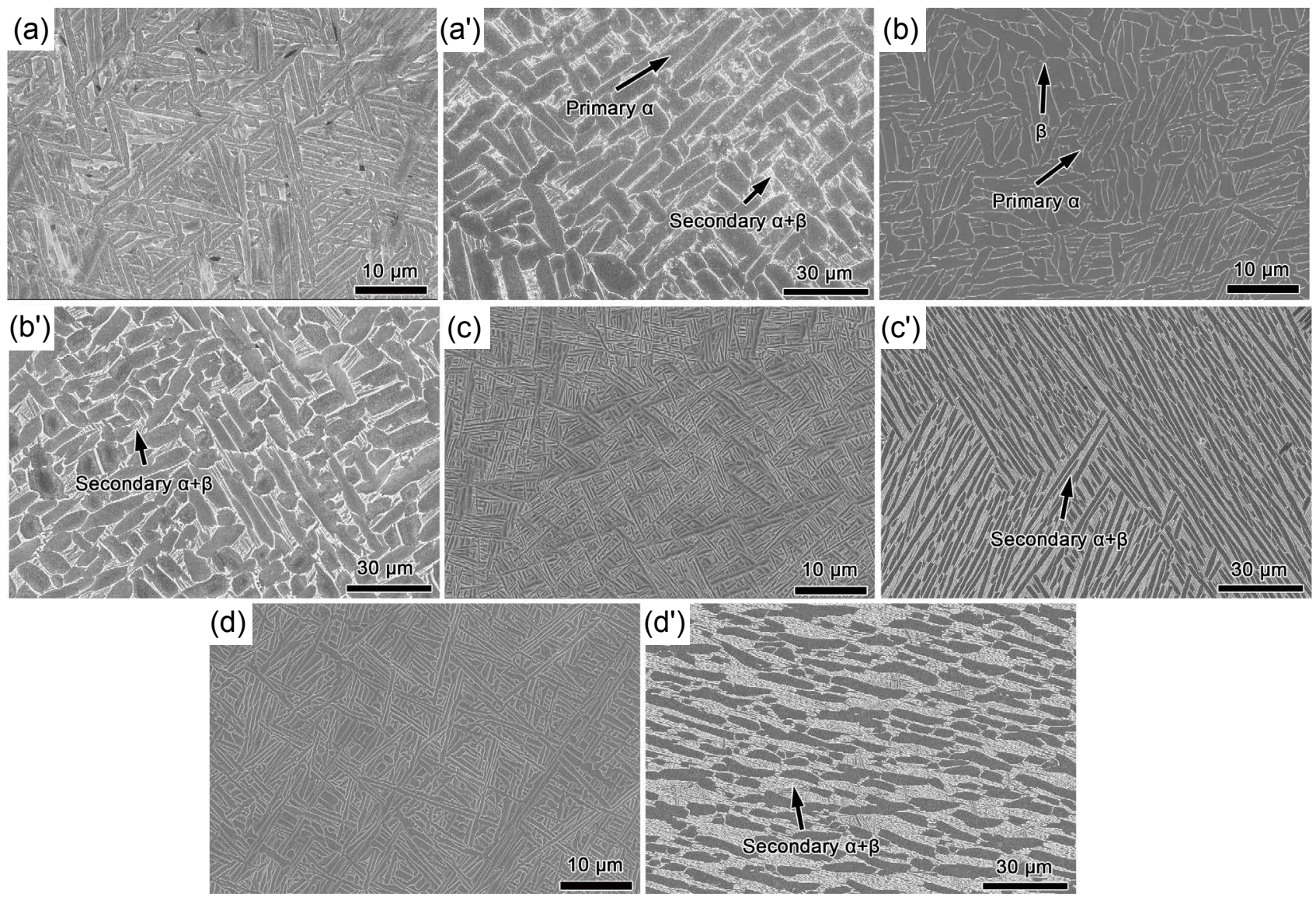

Fig. 6: SEM images of as-deposited (a-d) and heat-treated (a'-d') Ti-Al-V-Mo-Nb alloys: (a and a') Ti-6Al-4V; (b and b') 1.4Nb; (c and c') 3Mo; (d and d') 2Mo-1Nb
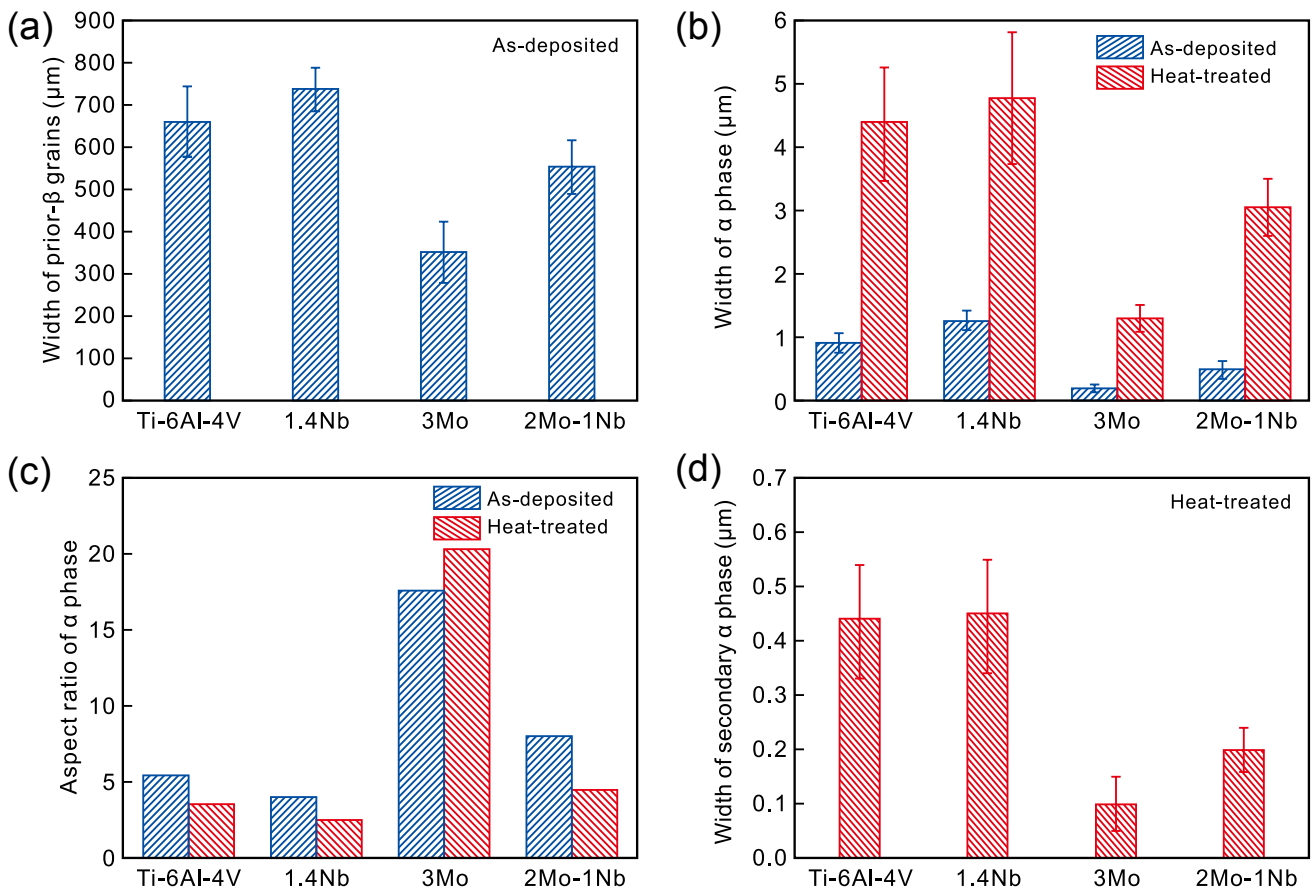

Fig. 7: Changes in prior- $\beta$ grains, primary $\alpha$, and secondary $\alpha$ phases of Ti-Al-V-Mo-Nb alloys: (a) width of prior- $\beta$ grains in as-deposited samples; (b) width of $\alpha$ phase; (c) aspect ratio; (d) width of secondary a phase in heat treatment samples

and $2 \mathrm{Mo}-1 \mathrm{Nb}$ alloys are $4.40 \mu \mathrm{m}, 4.81 \mu \mathrm{m}, 1.34 \mu \mathrm{m}$, and $3.09 \mu \mathrm{m}$, and the secondary $\alpha$ phases are $0.44 \mu \mathrm{m}, 0.45 \mu \mathrm{m}$, $0.10 \mu \mathrm{m}$ and $0.20 \mu \mathrm{m}$, respectively. Compared with Ti-6Al$4 \mathrm{~V}, 1.4 \mathrm{Nb}$, and $2 \mathrm{Mo}-1 \mathrm{Nb}$ alloys, there is a much greater aspect ratio of primary $\alpha$ in 3Mo alloy, as shown in Fig. 7(c). After heat treatment, the aspect ratio of Ti- $6 \mathrm{Al}-4 \mathrm{~V}, 1.4 \mathrm{Nb}$, and $2 \mathrm{Mo}-$ $1 \mathrm{Nb}$ alloys is reduced, whereas that increased in $3 \mathrm{Mo}$ alloy, respectively relative to that of each as-deposited alloy. 
The grain refinement of Mo-containing alloys is mainly determined by the number of nucleates and the grain growth rate ${ }^{[23,24]}$. On the one hand, the melting point of element Mo $\left(2,623{ }^{\circ} \mathrm{C}\right)$ is higher than those of $\mathrm{V}\left(1,902{ }^{\circ} \mathrm{C}\right)$ and $\mathrm{Nb}$ $\left(2,477^{\circ} \mathrm{C}\right)$, which leads to the melting rate of Mo being slow, meaning that it can provide more heterogeneous sites. On the other hand, the slower diffusion rate of solute elements, and the slower growth rate of grains, give rise to the finer grains ${ }^{[25]}$. Since the diffusion rate of Mo is also slower than those of $\mathrm{V}$ and $\mathrm{Nb}$, this reduces the grain growth rate for Mocontaining alloys during the LAM progress. Therefore, the grain size, especially the width of $\alpha$ phases for the $3 \mathrm{Mo}$ and $2 \mathrm{Mo}-1 \mathrm{Nb}$ alloys, is finer than those of the Ti-6Al-4V and $1.4 \mathrm{Nb}$ alloys, as shown in Fig. 6, which plays a key role in the strength improvement of the alloy. It is known that the aspect ratio of the $\alpha$ laths is determined by the length over width. When the $\alpha$ length is split by the $\beta$ phase that is enriched in $\beta$ stable elements, or there is a larger $\alpha$ width, this results in the reduction in the aspect ratio of the $\alpha$ laths ${ }^{[26-28]}$. In this study, the addition of Mo refines the width and increases the length of $\alpha$ laths, meanwhile, there is a smaller $\alpha$ width but its length is relative larger for Mo-containing alloys, as shown in Fig. 6, giving rise to an increase in its aspect ratio. In addition, the microstructures of titanium alloys are highly sensitive to the $\beta$-transus temperature. The $\beta$-transus temperatures of the Ti$6 \mathrm{Al}-4 \mathrm{~V}, 1.4 \mathrm{Nb}, 3 \mathrm{Mo}$, and $2 \mathrm{Mo}-1 \mathrm{Nb}$ alloys are $970{ }^{\circ} \mathrm{C}, 975^{\circ} \mathrm{C}$, $985^{\circ} \mathrm{C}$, and $990{ }^{\circ} \mathrm{C}$, respectively. Annealing at temperatures above the $\beta$-transus temperature in the $\beta$ phase leads to increased aspect ratios.

\subsection{Mechanical properties}

Figure 8 shows changes in the micro-hardness of cross sections in the middle of the as-deposited and heat-treated samples. For the as-deposited samples, the micro-hardness values of the Ti$6 \mathrm{Al}-4 \mathrm{~V}, 1.4 \mathrm{Nb}, 3 \mathrm{Mo}$, and $2 \mathrm{Mo}-1 \mathrm{Nb}$ alloys are $328,320,354$, and $336 \mathrm{HV}$, respectively, whereas the micro-hardness of the heat-treated Ti-6Al-4V, $1.4 \mathrm{Nb}, 3 \mathrm{Mo}$, and $2 \mathrm{Mo}-1 \mathrm{Nb}$ alloys are $332,327,371$, and $355 \mathrm{HV}$, respectively. Compared with the as-deposited samples, the micro-hardness values of all the alloys show a certain degree of improvement mainly due to the formation of fine secondary- $\alpha$ phases. Relative to Ti-6Al-4V and $1.4 \mathrm{Nb}$, a higher increment of micro-hardness is obtained in $3 \mathrm{Mo}$ and $2 \mathrm{Mo}-1 \mathrm{Nb}$ alloys, which results from the formation of a finer secondary $\alpha$ phase during heat treatment, as shown in Fig. 7(d).

Ultimate tensile strength (UTS), yield strength (YS), and elongation (EL) were measured, with the results displayed in Fig. 9. In terms of the as-deposited samples [Figs. 9(a) and (b)], compared with the ultimate tensile strength (977 MPa) and elongation (10\%) of the Ti-6Al-4V alloy, the $1.4 \mathrm{Nb}$ alloy exhibits a similar ultimate tensile strength (965 MPa) and a higher elongation (13\%), the $2 \mathrm{Mo}-1 \mathrm{Nb}$ alloy exhibits a slightly higher ultimate tensile strength (1,019 $\mathrm{MPa})$ and a similar elongation (10\%), and the $3 \mathrm{Mo}$ alloy exhibits a higher ultimate tensile strength $(1,075 \mathrm{MPa})$ but a relatively low elongation $(7 \%)$. In terms of the heat-treated samples

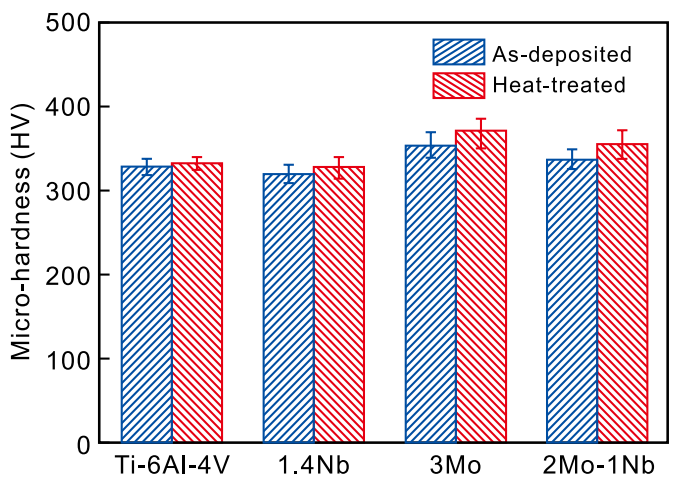

Fig. 8: Changes in micro-hardness of cross sections in middle of as-deposited and heat-treated Ti-Al-V-Mo-Nb alloys

[Figs. 9(c) and (d)], the elongation of the $1.4 \mathrm{Nb}$ alloy (15\%) is higher than that of the Ti-6Al-4V alloy (13\%), and the $3 \mathrm{Mo}$ and $2 \mathrm{Mo}-1 \mathrm{Nb}$ alloys exhibit higher strengths of $1,115 \mathrm{MPa}$ and 1,071 MPa, respectively. Compared with the Ti-6Al-4V alloy, the elongation of both the as-deposited and heat-treated $1.4 \mathrm{Nb}$ alloy is improved significantly, with their increment ratios maintaining at $26 \%$ and $17 \%$, respectively. The tensile strengths of $3 \mathrm{Mo}$ alloy are improved significantly, including as-deposited increased by $10 \%$ and heat-treated increased by $14 \%$, respectively, relative to each Ti-6Al-4V alloy.

It is commonly recognized that the strength (or microhardness) is a measure of the resistance to dislocation slip within the material. With a decrease in the widths of the primary $\alpha$ phase, the dislocation glide length within the primary $\alpha$ phase is decreased, which leads to an enhancement in the capacity of the dislocation storage ${ }^{[29,30]}$. The widths of the primary $\alpha$ phases in the as-deposited $3 \mathrm{Mo}$ and $2 \mathrm{Mo}-1 \mathrm{Nb}$ alloys are significantly smaller than those of the as-deposited Ti-6Al-4V and $1.4 \mathrm{Nb}$ alloys, as shown in Fig. 6, thus, the strength of the Mo-containing alloys is improved.

It is clear that the width of the primary $\alpha$ phase increases after heat treatment. Compared with the as-deposited samples, the strength is improved, especially that of the 3Mo and 2Mo$1 \mathrm{Nb}$ alloys, which can be attributed to the precipitation of the secondary $\alpha$ phase after heat treatment. According to research by Devaraj et al. ${ }^{[31]}$, the importance of the secondary $\alpha$ phase was proposed using the following relationship:

$$
\sigma \propto K_{\mathrm{P}} / l_{\mathrm{P}}+K_{\mathrm{S}} / l_{\mathrm{S}}
$$

where $\sigma$ is the strength, $K_{\mathrm{P}}$ and $K_{\mathrm{S}}$ are Taylor factor constants, and $l_{\mathrm{P}}$ and $l_{\mathrm{S}}$ are the inter-particle spacing of the primary $\alpha$ and secondary $\alpha$ phases, respectively. After heat treatment, the secondary $\alpha$ phase plays a major role in improving the strength of the alloy, which can be attributed to two factors. According to Eq. (1), the smaller lamella spacing of the secondary $\alpha$ phases leads to a decrease in the average distance between the dislocations from the secondary $\alpha$ lamella to the other secondary $\alpha$ lamella, which improves the strength. Moreover, the secondary $\alpha$ phase is finer than the primary $\alpha$ phase, and the dislocation glide length significantly decreases, which 

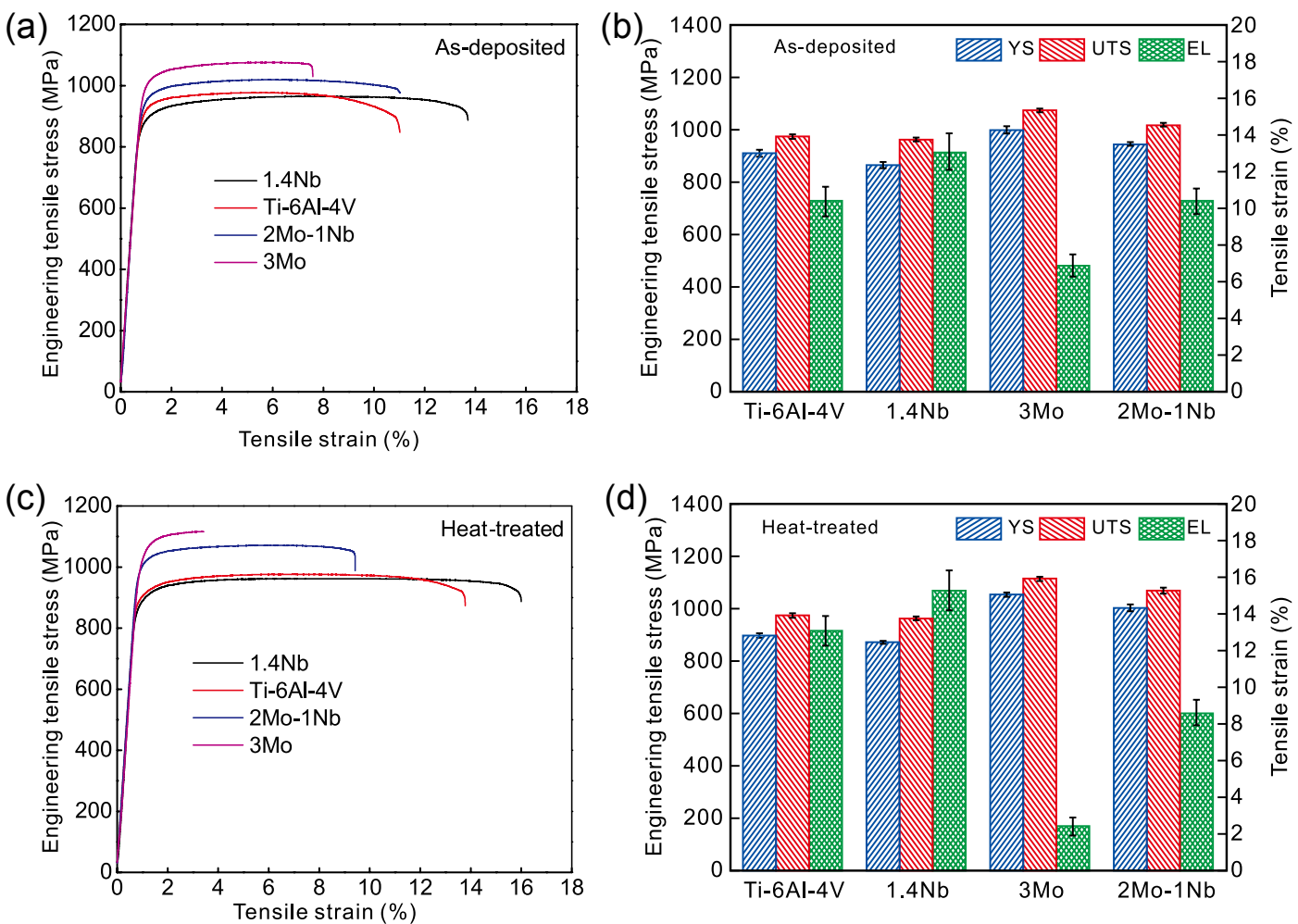

Fig. 9: Tensile properties of Ti-Al-V-Mo-Nb alloys under different conditions: ( $a$ and $b$ ) as-deposited samples; (c and d) heat-treated samples

improves the strength of the alloy. Compared with the Ti-6Al$4 \mathrm{~V}$ and $1.4 \mathrm{Nb}$ alloys, the width of the secondary $\alpha$ phase in the $3 \mathrm{Mo}$ and $2 \mathrm{Mo}-1 \mathrm{Nb}$ alloys is finer, and this leads to the strength improvement, with slightly lows the elongation. Overall, the simultaneous addition of $\mathrm{Mo} / \mathrm{Nb}$ improves the comprehensive mechanical properties of the alloys in this study.

\subsection{Fracture morphology}

Figure 10 shows the room temperature tensile fracture morphologies of the as-deposited Ti-Al-V-Mo-Nb alloys, from which there are mixed-fracture characteristics consisting of cleavage and dimple fractures in the Ti-6Al-4V, $1.4 \mathrm{Nb}, 3 \mathrm{Mo}$, and $2 \mathrm{Mo}-1 \mathrm{Nb}$ samples. Among these images, Figs. 10(a and b) and ( $\mathrm{g}$ and $\mathrm{h}$ ) show that microcracks are mainly distributed along the boundaries of the cleavage facets and tear ridges in the Ti-6Al-4V and 2Mo-1 Nb alloys. As can be seen from Figs. $10(\mathrm{c})$ and (d), there are fewer cleavage facets and tear ridges in $1.4 \mathrm{Nb}$, meaning that it features fewer nucleation sources to form microcracks, and it has more dimples that can effectively release internal stress; therefore, this material exhibits better plasticity. In comparison, Figs. 10(e) and (f) show that there are coarse cleavage facets and tear ridges concentrated in the fracture surface. The boundaries of the tear ridges and cleavage facets are the main nucleation sources for microcracks to form due to the ready formation of a pile-up of dislocations ${ }^{[32]}$, which decreases the elongation of the material, meaning that the 3 Mo alloy exhibits the worst plasticity among the alloy samples.
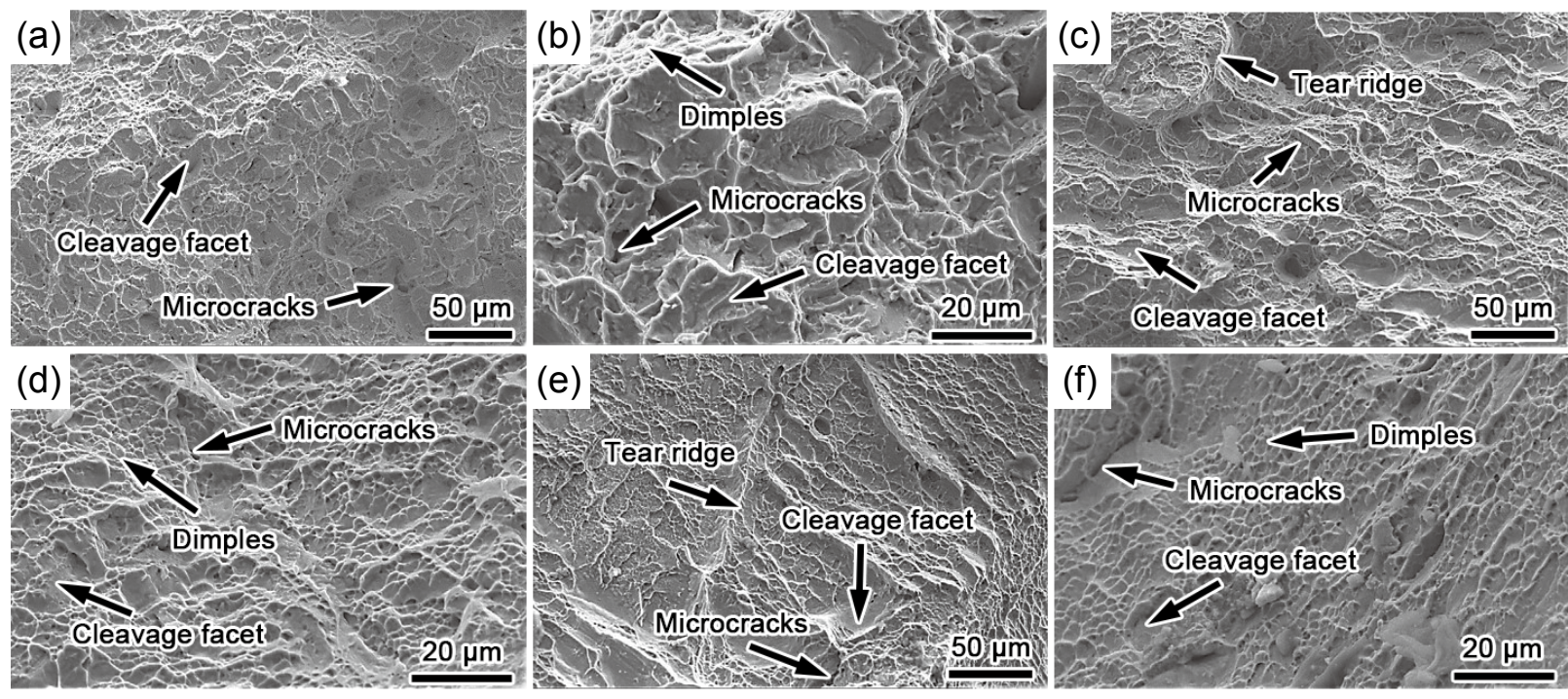

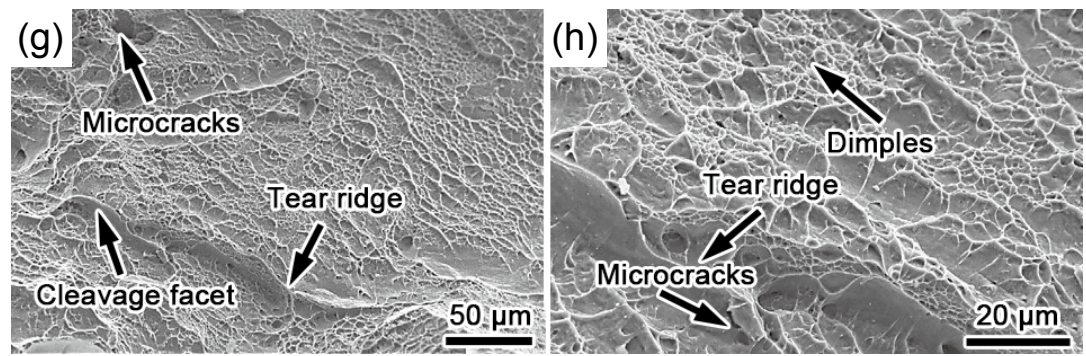

Fig. 10: SEM images of fracture morphologies of as-deposited Ti-Al-V-Mo-Nb alloys: (a and b) Ti-6Al-4V; (c and d) 1.4Nb; (e and f) $3 \mathrm{Mo}$; (g and h) $2 \mathrm{Mo}-1 \mathrm{Nb}$

Figure 11 shows SEM images of the room temperature tensile fracture morphologies of the heat-treated Ti-Al-V-Mo-Nb alloys. Similar to the as-deposited samples, the mixed-fracture characteristics of the cleavage fractures and dimples in the Ti$6 \mathrm{Al}-4 \mathrm{~V}, 1.4 \mathrm{Nb}, 3 \mathrm{Mo}$, and $2 \mathrm{Mo}-1 \mathrm{Nb}$ alloys with microcracks are mainly distributed along the boundaries of cleavage facets. Compared with the as-deposited alloys, for the heat-treated samples, there are increases in the number of cleavage facets and dimple size due to the growth of grains during the heat treatment process. Figures 11( $a$ and $b$ ) and ( $g$ and $h$ ) show SEM images of the fracture morphologies of the Ti-6Al-4V and $2 \mathrm{Mo}-1 \mathrm{Nb}$ alloys, from which can be seen that microcracks are distributed along the boundaries between the cleavage faces and tear ridges. As can be seen in Figs. 11(c) and (d), the 1.4Nb alloy has fewer cleavage facets and tear ridges, resulting in fewer nucleation sources of microcracks, whereas it has more dimples and a large size that both lead to the alloy exhibiting better plasticity. In comparison, Figs. 11(e) and (f) show that the 3Mo alloy has coarse tear ridges concentrated in its fracture surface that leads to this material exhibiting poor plasticity.
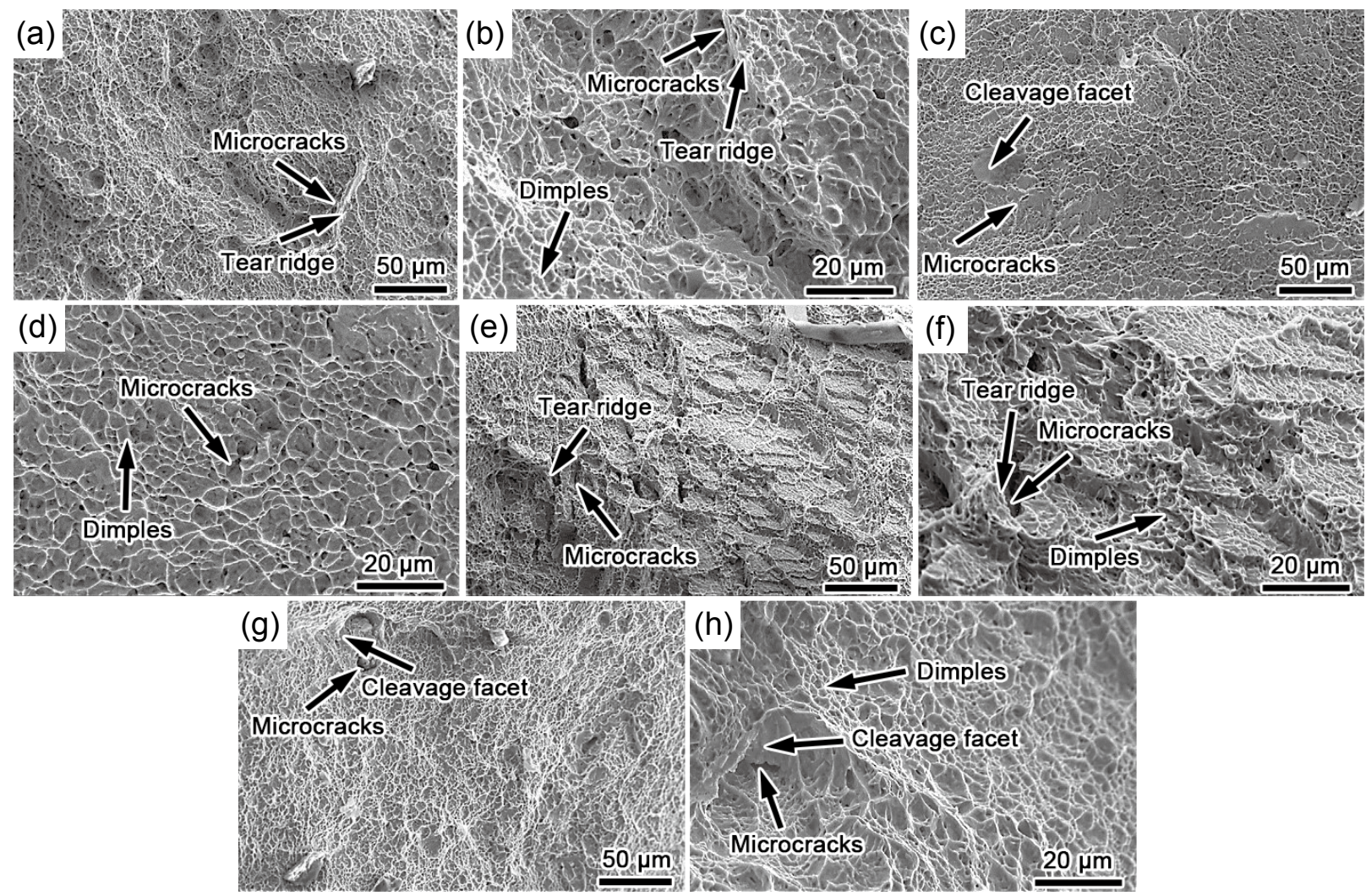

Fig. 11: SEM images of fracture morphologies of heat-treated Ti-Al-V-Mo-Nb alloys: (a and b) Ti-6Al-4V; (c and d) 1.4Nb; (e and f) 3Mo; (g and h) 2Mo-1 Nb

\section{Conclusions}

According to the Ti-6Al-4V alloy cluster composition formula, Ti-Al-V-Mo-Nb alloys suitable for LAM were prepared in the form of $12\left[\mathrm{Al}_{-} \mathrm{Ti}_{12}\right]\left(\mathrm{AlTi}_{2}\right)+5\left[\mathrm{Al}^{-\mathrm{Ti}_{14}}\right]\left((\mathrm{V}, \mathrm{Mo}, \mathrm{Nb})_{2} \mathrm{Ti}\right)$ by partially replacing $\mathrm{V}$ with $\mathrm{Nb} / \mathrm{Mo}$. The microstructure, microhardness, and tensile properties of the as-deposited and heattreated samples were investigated. The main conclusions can be drawn as follows:
(1) The cluster composition formula of the Ti-Al-V-Mo-Nb samples is proposed to be $12\left[\mathrm{Al}^{-\mathrm{Ti}_{12}}\right]\left(\mathrm{AlTi}_{2}\right)+5\left[\mathrm{Al}-\mathrm{Ti}_{14}\right]((\mathrm{Mo}$, $\left.\mathrm{V}, \mathrm{Nb})_{2} \mathrm{Ti}\right)$, wherein the $\beta$ clusters in the alloy are $\left[\mathrm{Al}-\mathrm{Ti}_{14}\right]$ $\left(\mathrm{V}_{2} \mathrm{Ti}\right),\left[\mathrm{Al}-\mathrm{Ti}_{14}\right]\left(\mathrm{V}_{1.6} \mathrm{Nb}_{0.4} \mathrm{Ti}\right)$, [Al-Ti $\left.\mathrm{A}_{14}\right]\left(\mathrm{V}_{1.2} \mathrm{Mo}_{0.8} \mathrm{Ti}\right)$, and [Al$\left.\mathrm{Ti}_{14}\right]\left(\mathrm{V}_{1.2} \mathrm{Mo}_{0.6} \mathrm{Nb}_{0.2} \mathrm{Ti}\right)$, respectively.

(2) The sizes of $\beta$ columnar grains and primary $\alpha$ phases in the as-deposited $1.4 \mathrm{Nb}$ alloy are relatively larger than those of the Ti-6Al-4V alloy, whereas they are significantly finer in 
the $3 \mathrm{Mo}$ and $2 \mathrm{Mo}-1 \mathrm{Nb}$ alloys, particularly the aspect ratio of primary $\alpha$ in $3 \mathrm{Mo}$ alloy is larger. The results indicate that $\mathrm{Nb}$ can coarsen $\beta$ columnar grains and $\alpha$ laths, whereas Mo can effectively refine prior- $\beta$ grains.

(3) Compared with the Ti-6Al-4V alloy, the elongation of both the as-deposited and heat-treated $1.4 \mathrm{Nb}$ alloy is improved significantly, with their increment percentages maintaining at $26 \%$ and $17 \%$, respectively. The tensile strengths of both as-deposited and heat-treated condition 3Mo alloys are improved obviously, with the increment percentages maintaining at $10 \%$ and $14 \%$, respectively. Ti-Al-V-Mo-Nb alloys exhibit ductile-brittle mixed fracture in both as-deposited and heat-treated conditions. Overall, it is found that the simultaneous addition of $\mathrm{Mo} / \mathrm{Nb}$ improves the comprehensive mechanical properties of the alloys in this study.

\section{Acknowledgements}

This work was supported by the National Key Research and Development Program of China (No. 2016YFB1100103), and the Key Discipline and Major Project of Dalian Science and Technology Innovation Foundation (No. 2020JJ25CY004).

\section{References}

[1] Li G C, Li J, Tian X J, et al. Microstructure and properties of a novel titanium alloy Ti-6Al-2V-1.5Mo-0.5Zr-0.3Si manufactured by laser additive manufacturing. Mater. Sci. Eng. A, 2017, 684: 233-238.

[2] Banerjee D, Williams J C. Perspectives on titanium science and technology. Acta Mater., 2013, 61: 844-879.

[3] Roger R R. An overview on the use of titanium in the aerospace industry. Mater. Sci. Eng. A, 1996, 213: 103-114.

[4] Weng F, Chen C Z, Yu H J. Research status of laser cladding on titanium and its alloys: A review. Mater. Des., 2014, 58: 412-425.

[5] Herzog D, Seyda V, Wycisk E, et al. Additive manufacturing of metals. Acta Mater., 2016, 117: 371-392.

[6] Lewandowski J J, Seifi M. Metal additive manufacturing: A review of mechanical properties. Annu. Rev. Mater. Res., 2016, 46: 14.1-14.36.

[7] Gu D D, Meiners W, Wissenbach K, et al. Laser additive manufacturing of metallic components: Materials, processes and mechanisms. Int. Mater. Rev., 2013, 57: 133-164.

[8] Mendoza M Y, Samimi P, Brice D A, et al. Microstructures and grain refinement of additive-manufactured Ti- $x \mathrm{~W}$ alloys. Metall. Mater. Trans. A., 2017, 48A: 3594-3605.

[9] Fischer $M$, Joguet $D$, Robin $G$, et al. In situ elaboration of a binary Ti-26Nb alloy by selective laser melting of elemental titanium and niobium mixed powders. Mat. Sci. Eng. C., 2016, 62: 852-859.

[10] Sing S L, Yeong W Y, Wiria F E. Selective laser melting of titanium alloy with 50wt.\% tantalum: Microstructure and mechanical properties. J. Alloy. Compd., 2016, 660: 461-470.

[11] Vrancken B, Thijs L, Kruth J P, et al. Microstructure and mechanical properties of a novel $\beta$ titanium metallic composite by selective laser melting. Acta Mater., 2014, 68: 150-158.

[12] Li G C, Li J, Tian X J, et al. Microstructure and properties of a novel titanium alloy Ti-6Al-2V-1.5Mo-0.5Zr-0.3Si manufactured by laser additive manufacturing. Mater. Sci. Eng. A., 2017, 684: 233-238.
[13] Yu Q, Wang C S, Wang D, et al. Microstructure and properties of $\mathrm{Ti}-\mathrm{Zr}$ congruent alloy fabricated by laser additive manufacturing. J. Alloy. Compd., 2020, 834: 155087.

[14] Dong C, Wang Q, Qiang J B, et al. From clusters to phase diagrams: Composition rules of quasicrystals and bulk metallic glasses. J. Phys. D: Appl. Phys., 2007, 40: 273-291.

[15] Qian S N, Dong C, Liu T Y, et al. Solute-homogenization model and its experimental verification in Mg-Gd-based alloys. J. Mater. Sci. Technol., 2018, 34: 1132-1141.

[16] Dong C, Wang Z J, Zhang S, et al. Review of structural models for the compositional interpretation of metallic glasses. Int. Mater. Rev., 2019, 65(5): 286-296.

[17] Takeuchi A, Inoue A. Classification of bulk metallic glasses by atomic size difference, heat of mixing and period of constituent elements and its application to characterization of the main alloying element. Mater. Trans., 2005, 46(12): 2817-2829.

[18] Jiang B B, Wang Q, Wen D H, et al. Effects of $\mathrm{Nb}$ and $\mathrm{Zr}$ on structural stabilities of Ti-Mo-Sn-based alloys with low modulus. Mater. Sci. Eng. A., 2017, 687: 1-7.

[19] Ma Y, Wang Q, Zhou X Y, et al. A novel soft-magnetic B2based multi-principal-element alloy with a uniform distribution of coherent body-centered-cubic nanoprecipitates. Adv. Mater., 2021, 33: 2006723.

[20] Jiang B B, Wen D H, Wang Q, et al. Design of near-a Ti alloys via a cluster formula approach and their high-temperature oxidation resistance. J. Mater. Sci. Technol., 2019, 35: 10081016.

[21] Cai J M, Cao C X. Alloy design and application expectation of a new generation $600{ }^{\circ} \mathrm{C}$ high temperature titanium alloy. J. Aeronaut. Mater., 2014, 34(4): 27-36.

[22] Liu T Y, Zhang S, Wang Q, et al. Composition formulas of $\mathrm{Ti}$ alloys derived by interpreting Ti-6Al-4V. Sci. China Tech. Sci., 2021, 64: 1732-1740.

[23] Zhang D Y, Qiu D, A. Gibson M, et al. Additive manufacturing of ultrafine-grained high-strength titanium alloys. Nature, 2019, 576(7785): 91-95.

[24] Hao Y L, Li S J, Sun S Y, et al. Effect of Zr and Sn on Young's modulus and superelasticity of Ti-Nb based alloys. Mater. Sci. Eng. A., 2006, 441(1): 112-118.

[25] Ikeda M, Shin-Ya K, Nakamura Y. Effects of Sn and Zr additions on phase constitution and aging behavior of Ti-50 mass $\%$ Ta alloys quenched from $\beta$ single phase region. Mater. Trans., 2004, 45(4): 1106-1112.

[26] Xing W T, Kalidindi A R, Amram D, et al. Solute interaction effects on grain boundary segregation in ternary alloys. Acta Mater., 2018, 161: 285-294.

[27] Zhao Z, Chen J, Tan H, et al. Achieving superior elongation for laser solid formed extra low interstitial Ti-6Al-4V titanium alloy through equiaxial alpha microstructure. Scripta Mater., 2018, 146: 187-191.

[28] Rou S, Karanth S, Suwas S. Microstructure and texture evolution during sub-transus thermos-mechanical processing of Ti-6Al-4V-0.1 B alloy: Part II. Static annealing in $(\alpha+\beta)$ regime. Metall. Trans., 2013, 34(3): 3322-3336.

[29] Sabban R, Bahl S, Chatterjee K, et al. Globularization using heat treatment in additively manufactured Ti-6Al-4V for high strength and toughness. Acta Mater., 2019, 162: 239-254.

[30] Niinomi M, Kobayashi T, Sasaki S. Toughness and microstructural factors of Ti-6Al-4V alloy. Mater. Sci. Eng., 1988, 100: 45-50.

[31] Devaraj A, Joshi V V, Srivastava A, et al. A low-cost hierarchical nanostructured beta-titanium alloy with high strength. Nat. Commun., 2016, 7: 11176.

[32] Raganya L, Moshokoa N, Obadele B A, et al. Investigation of the tensile properties of heat treated Ti-Mo alloys. Mater. Today: Proc., 2021, 38: 1044-1048. 